\title{
Influence of the IL6 Gene in Susceptibility to Systemic Sclerosis
}

\author{
MARIA CARMEN CÉNIT, CARMEN P. SIMEÓN, MADELON C. VONK, JOSE L. CALLEJAS-RUBIO, \\ GERARD ESPINOSA, PATRICIA CARREIRA, FRANCISCO J. BLANCO, JAVIER NARVAEZ, CARLOS TOLOSA, \\ JOSÉ A. ROMÁN-IVORRA, INMACULADA GÓMEZ-GARCÍA, FRANCISCO J. GARCÍA-HERNÁNDEZ, \\ MARÍA GALLEGO, ROSA GARCÍA-PORTALES, MARÍA VICTORIA EGURBIDE, VICENTE FONOLLOSA, \\ PALOMA GARCÍA de la PEÑA, FRANCISCO J. LÓPEZ-LONGO, MIGUEL A. GONZÁLEZ-GAY and the Spanish \\ Scleroderma Group, ROGER HESSELSTRAND, GABRIELA RIEMEKASTEN, TORSTEN WITTE, \\ ALEXANDRE E. VOSKUYL, ANNEMIE J. SCHUERWEGH, RAJAN MADHOK, CARMEN FONSECA, \\ CHRISTOPHER DENTON, ANNIKA NORDIN, ØYVIND PALM, JACOB M. van LAAR, NICOLAS HUNZELMANN, \\ JÖRG H.W. DISTLER, ALEXANDER KREUTER, ARIANE HERRICK, JANE WORTHINGTON, BOBBY P. KOELEMAN, \\ TIMOTHY R.D.J. RADSTAKE, and JAVIER MARTÍN
}

ABSTRACT. Objective. Systemic sclerosis (SSc) is a genetically complex autoimmune disease; the genetic component has not been fully defined. Interleukin 6 (IL-6) plays a crucial role in immunity and fibrosis, both key aspects of SSc. We investigated the influence of IL6 gene in the susceptibility and phenotype expression of SSc.

Methods. We performed a large metaanalysis including a total of 2749 cases and 3189 controls from 6 white populations (Germany, The Netherlands, Norway, Spain, Sweden, and United Kingdom). Three IL6 single-nucleotide polymorphisms (SNP; rs2069827, rs1800795, and rs2069840) were selected by SNP tagging and genotyped using TaqMan ${ }^{\circledR}$ allele discrimination technology.

Results. Individual SNP metaanalysis showed no evidence of association of the 3 IL6 genetic variants with the global disease. Phenotype analyses revealed a significant association between the minor allele of rs2069840 and the limited cutaneous SSc clinical form (Bonferroni $\mathrm{p}=0.036$, OR $1.14,95 \%$ CI 1.04-1.25). A trend of association between the minor allele of the rs 1800795 and the diffuse cutaneous SSc clinical form was also evident (Bonferroni $\mathrm{p}=0.072$, OR 0.86, 95\% CI 0.77-0.96). In the IL6 allelic combination analyses, the GGC allelic combination rs2069827-rs1800795-rs2069840 showed an association with overall SSc (Bonferroni $\mathrm{p}=0.016, \mathrm{OR}$ $1.13,95 \%$ CI $1.04-1.23)$.

Conclusion. Our results suggest that the IL6 gene may influence the development of SSc and its progression. (First Release Oct 1 2012; J Rheumatol 2012;39:2294-302; doi:10.3899/jrheum.120506)

Key Indexing Terms:

SYSTEMIC SCLEROSIS

SCLERODERMA

IL6 GENE

POLYMORPHISMS

GENETIC STUDIES

From the Instituto de Parasitología y Biomedicina López-Neyra, IPBLN-CSIC, Granada; Department of Internal Medicine, Hospital Valle de Hebron, Barcelona, Spain; Department of Rheumatology, Radboud University Nijmegen Medical Center, Nijmegen, The Netherlands; Department of Internal Medicine, Hospital Clínico Universitario, Granada; Department of Internal Medicine, Hospital Clínico de Barcelona, Barcelona; Department of Rheumatology, Hospital 12 de Octubre, Madrid; Complejo Hospitalario Universitario a Coruña, La Coruña; Department of Rheumatology, Hospital de Bellvitge, Barcelona; Department of Internal Medicine, Hospital Parc Tauli, Sabadell; Department of Rheumatology, Hospital La Fe, Valencia; Department of Rheumatology, Hospital Reina Sofía, Córdoba; Department of Internal Medicine, Hospital Virgen del Rocío, Sevilla; Department of Internal Medicine, Hospital Central de Asturias, Oviedo; Department of Rheumatology, Hospital Virgen de la Victoria, Málaga; Department of Internal Medicine, Hospital de Cruces, Barakaldo; Department of Rheumatology, Hospital Madrid Norte Sanchinarro, Madrid; Department of Rheumatology, Hospital General Universitario Gregorio Marañon; Department of Rheumatology, Hospital Universitario Marqués de Valdecilla, IFIMAV, Santander, Spain; Department of Rheumatology, Lund University, Lund, Sweden; German Rheumatismus Research Centre, Leibniz Institute, Germany; Clinic for Immunology and Rheumatology
Medical School, Hannover, Germany; Department of Rheumatology, VU University Medical Center, Amsterdam; Department of Rheumatology, Leiden University Medical Center, Leiden, The Netherlands; Centre for Rheumatic Disease University of Glasgow, Glasgow; Centre for Rheumatology, Royal Free and University College Medical School, London, UK; Center for Molecular Medicine, Karolinska Institute, Stockholm, Sweden; Department of Rheumatology, Rikshospitalet, Oslo University Hospital, Oslo, Norway; Institute of Cellular Medicine, Newcastle University, Newcastle, UK; Department of Dermatology, University of Cologne, Cologne; Department of Internal Medicine 3, Institute for Clinical Immunology, University of Erlangen-Nuremberg, Erlangen; Klinik für Dermatologie, Venerologie und Allergologie, Ruhr University of Bochum, Bochum, Germany; Arthritis Research UK Epidemiology Unit, The University of Manchester, Manchester Academic Health Science Centre, Manchester, UK; Department of Medical Genetics, University Medical Center Utrecht, Utrecht; and Department of Rheumatology and Clinical Immunology, Utrecht Medical Center, Utrecht, The Netherlands.

J. Martin was supported by GEN-FER from the Spanish Society of Rheumatology, SAF2009-11110 from the Spanish Ministry of Science, CTS-180 from Junta de Andalucía, RETICS Program, RD08/0075 (RIER) from Instituto de Salud Carlos III (ISCIII), Spain, within the VI PN de 
I+D+i 2008-2011 (FEDER). T.R.D.J. Radstake and J. Martín are sponsored by the Orphan Disease Program grant from European League Against Rheumatism. N. Ortego-Centeno and J. Martín are supported by Consejería de Salud, Junta de Andalucía, PI-0590-2010.

M.C. Cénit, PhD; J. Martín, MD, PhD, IPBLN-CSIC; C.P. Simeón, MD, PhD; V. Fonollosa, MD, PhD, Department of Internal Medicine, Hospital Valle de Hebron; M.C. Vonk, MD, PhD, Department of Rheumatology, Radboud University Nijmegen Medical Center; J.L. Callejas-Rubio, MD, PhD, Department of Internal Medicine, Hospital Clínico Universitario, G. Espinosa, MD, PhD, Department of Internal Medicine, Hospital Clínico de Barcelona; P. Carreira, $M D, P h D$, Department of Rheumatology, Hospital 12 de Octubre; F.J. Blanco, MD, PhD, Complejo Hospitalario Universitario a Coruña; J. Narvaez, MD, PhD, Department of Rheumatology, Hospital de Bellvitge; C. Tolosa, MD, PhD, Department of Internal Medicine, Hospital Parc Tauli;

J.A. Román-Ivorra, MD, PhD, Department of Rheumatology, Hospital La Fe; I. Gómez-García, MD, PhD, Department of Rheumatology, Hospital Reina Sofía, Córdoba; F.J. García-Hernández, MD, PhD, Department of Internal Medicine, Hospital Virgen del Rocío; M. Gallego, MD, PhD, Department of Internal Medicine, Hospital Central de Asturias; R. García-Portales, MD, PhD, Department of Rheumatology, Hospital Virgen de la Victoria; M.V. Egurbide, MD, PhD, Department of Internal Medicine, Hospital de Cruces; P. García de la Peña, MD, PhD, Department of Rheumatology, Hospital Madrid Norte Sanchinarro; F.J. López-Longo, MD, PhD, Department of Rheumatology, Hospital General Universitario Gregorio Marañón; M.A. González-Gay, MD, PhD, Department of Rheumatology, Hospital Universitario Marqués de Valdecilla, IFIMAV; R. Hesselstrand, MD, PhD, Department of Rheumatology, Lund University; G. Riemekasten, MD, PhD, German Rheumatismus Research Centre, Leibniz Institute; T. Witte, MD, PhD, Clinic for Immunology and Rheumatology Medical School; A.E. Voskuyl, $M D, P h D$, Department of Rheumatology, VU University Medical Center, A.J. Schuerwegh, MD, PhD, Department of Rheumatology, Leiden University Medical Center; R. Madhok, MD, PhD, Centre for Rheumatic Disease University of Glasgow; C. Fonseca, MD, PhD; C. Denton, MD, PhD, Centre for Rheumatology, Royal Free and University College Medical School; A. Nordin, MD, PhD, Center for Molecular Medicine, Karolinska Institute; Ø. Palm, MD, PhD, Department of Rheumatology, Rikshospitalet, Oslo University Hospital; J.M. van Laar, MD, PhD, Institute of Cellular Medicine, Newcastle University; N. Hunzelmann, MD, PhD, Department of Dermatology, University of Cologne; J.H.W. Distler, MD, PhD, Department of Internal Medicine 3, Institute for Clinical Immunology, University of Erlangen-Nuremberg; A. Kreuter, $M D, P h D$, Klinik für Dermatologie, Venerologie und Allergologie, Ruhr University of Bochum; A. Herrick, MD, PhD; J. Worthington, MD, PhD, Arthritis Research UK Epidemiology Unit, The University of Manchester, Manchester Academic Health Science Centre; B.P. Koeleman, MD, PhD, Department of Medical Genetics, University Medical Center Utrecht; T.R.D.J. Radstake, MD, PhD, Department of Rheumatology and Clinical Immunology, Utrecht Medical Center.

Address correspondence to M.C. Cénit, Instituto de Parasitología y Biomedicina López-Neyra, IPBLN-CSIC, Parque Tecnológico Ciencias de la Salud, Avenida del Conocimiento, s/n 18100 Armilla, Granada, Spain. E-mail: mccenit@ipb.csic.es

Accepted for publication July 4, 2012.

Systemic sclerosis (SSc) is a genetically complex disease clinically characterized by progressive fibrosis of the skin and internal organs, vascular damage, and autoimmune events. Two major subgroups in the commonly accepted classification of SSc are determined in the prognostic differentiation: limited cutaneous scleroderma (lcSSc) and diffuse cutaneous scleroderma ( $\mathrm{dcSSc})$. Anticentromere antibodies (ACA) and antitopoisomerase antibodies (ATA) are 2 almost mutually exclusive SSc-associated autoantibodies that correlate with these distinct clinical subsets ${ }^{1}$.
Familial clustering and ethnic influences support the genetic component of this disease ${ }^{2}$. Initially, only MHC genes were firmly associated with $\mathrm{SSc}^{3}$. Current genetic studies, including genome-wide association studies (GWAS), have shown that several genes located within non-MHC chromosomal regions also contribute to SSc susceptibility and clinical features ${ }^{4,5,6}$. However, the genetic component of SSc and its clinical subsets remain to be elucidated ${ }^{3}$.

Interleukin 6 (IL-6) is a pleiotropic cytokine that plays a crucial role in both adaptive and innate immunity and in the link between them. It is produced by a variety of cell types, including lymphocytes, monocytes, and fibroblasts, in response to inflammatory stimuli; and it exerts proinflammatory and antiinflammatory functions ${ }^{7}$. IL- 6 induces the production of collagen by dermal fibroblasts, and investigators have demonstrated higher production of IL- 6 by fibroblasts in $\mathrm{SSc}^{8,9}$ contributing to skin fibrosis ${ }^{10}$. High IL-6 levels have been reported in both skin and serum of patients with SSc, apparently correlating with the presence of lung involvement ${ }^{11,12,13}$. Further, IL-6 induces development of Th17 cells and inhibits development of regulatory $\mathrm{T}$ cells $\left(\mathrm{T}_{\text {reg }}\right)^{14}$, modulating the Th17/T reg balance that is involved in SSc pathogenesis ${ }^{15}$. Current studies reveal a possible beneficial effect of anti-IL-6 receptor antibody therapy (tocilizumab) for patients with SSc, supporting the crucial role of IL-6 in SSc pathophysiology ${ }^{16}$.

It is well known that the IL6 gene is mainly regulated at the transcriptional level, and several polymorphisms affecting transcription have been reported to influence final IL-6 levels ${ }^{17,18}$. A promoter $I L 6-174 * \mathrm{G}$ allele has been associated with risk for systemic-onset juvenile chronic arthritis ${ }^{19}$ and systemic lupus erythematosus ${ }^{20}$, diseases that share a substantial genetic component with $\mathrm{SSc}^{3}$.

Considering all these findings, we investigated the potential contribution of $I L 6$ gene variants to susceptibility to SSc and its major clinical phenotypes.

\section{MATERIALS AND METHODS}

Study population. A large multicenter case-control study was carried out including a total of 3189 controls and 2749 cases from 6 European populations of white ancestry (Germany, The Netherlands, Norway, Spain, Sweden, and United Kingdom). The control population consisted of unrelated healthy individuals recruited in the same geographical regions as patients and matched for ethnicity. Approval from the local ethical committees and written informed consent from all participants were obtained.

Patients with SSc were diagnosed according to the 1980 American College of Rheumatology classification criteria ${ }^{21}$, and were subdivided into those with $\mathrm{lcSSc}$ and dcSSc as defined by LeRoy, et $a l^{22}$, and by autoantibody status based on the presence/absence of ACA or ATA. The presence of the SSc-specific autoantibodies antitopoisomerase I (anti-Scl70) and ACA was assessed by passive immunodiffusion against calf thymus extract (Inova Diagnostics) and indirect immunofluorescence of HEp-2 cells (Antibodies Inc.), respectively. Additionally, fibrotic lung was assessed in patients with SSc, defined as the presence of typical features on high-resolution computed tomography of the chest, as described ${ }^{23}$.

Single-nucleotide polymorphism selection and genotyping. We analyzed 3 single-nucleotide polymorphisms (SNP) located within the IL6 gene, on

Personal non-commercial use only. The Journal of Rheumatology Copyright $\subset$ 2012. All rights reserved. 
chromosome 7 , that tag over $80 \%$ of the variability of this locus: rs2069827, rs1800795, and rs2069840. Tagging was performed using the "aggressive tagging" option in the Haploview software v4.2 (website: http://broad.mit.edu/mpg/haploview), with the $\mathrm{r}^{2}$ threshold set at 0.8 and minimum minor allele frequency at 0.1 . The inclusion of the rs 1800795 polymorphism $(-174 \mathrm{G} / \mathrm{C})$ located in the promoter of this gene was forced in our study.

Genomic DNA was extracted from peripheral white blood cells following standard procedures. Samples were genotyped for the IL6 genetic variants using TaqMan ${ }^{\circledR}$ 5' allele discrimination assays (rs2069827 and rs2069840 were predesigned assays with identification C__15860047_10 and C__15804104_10; and rs1800795 was designed as a custom assay) in a 7900HT Fast Real-Time PCR System (Applied Biosystems).

The 3 selected SNP are in a linkage disequilibrium block of $D^{\prime}=1$ and their correlation values measured by the $\mathrm{r}^{2}$ coefficient were 0.097 between rs2069827 and rs1800795, 0.051 between rs2069827 and rs2069840, and 0.476 between rs1800795 and rs2069840 (data from the International HapMap Project, Website: http://www.hapmap. org).

Statistical analysis. Hardy-Weinberg equilibrium was tested for all SNP at significance level $=0.01$. Genotyping success was greater than $95 \%$ for all polymorphisms.

Association was calculated by $2 \times 2$ contingency tables and/or Fisher's exact test when necessary, obtaining $\mathrm{p}$ values, OR and 95\% CI using PLINK (v1.07; http://pngu. mgh.harvard.edu/purcell/plink/). Allelic combinations were constructed using PLINK and Haploview v4.2 using the expectation-maximization algorithm implemented in the program for all samples included in the case-control study (excluding individuals with $>$ $40 \%$ missing genotypes). Allelic combinations represented in over $5 \%$ of the healthy controls in any of the 6 study populations were selected for pooled analysis. Multiple testing corrections were applied to the resulting $\mathrm{p}$ values with Bonferroni correction. Bonferroni correction was applied in the haplotype-based association analysis by dividing the detected significance level by the number of major haplotypes detected (frequency $>5.0 \%$ ). After correction, $\mathrm{p}$ values $<0.05$ were considered statistically significant.
The metaanalysis was carried out using PLINK (v1.07) and Review Manager (RevMan 5.0). Homogeneity among cohorts was calculated using the Breslow-Day test, and overall OR calculations were performed under a fixed-effects Mantel-Haenszel model.

\section{RESULTS}

Genotypic and allelic frequencies for the pooled analysis of the 3 selected IL6 SNP are shown in Table 1; and genotype and allelic frequencies for 6 national subpopulations are shown in Appendixes 2 to 7. In the different metaanalyses performed, the Breslow-Day test revealed no significant heterogeneity among OR of the different populations in the SNP separately or in their allelic combinations $(\mathrm{p}>0.05)$. Independent metaanalysis of the 3 SNP showed no evidence of association with the global disease (Table 1). However, the Mantel-Haenszel test of the different allelic combinations of the SNP, including sex as a covariate, showed a statistically significant association between the rs2069827-rs1800795-rs2069840 GGC allelic combination and global disease risk after Bonferroni correction for multiple testing ( $\mathrm{p}=0.014$, OR $1.14,95 \%$ CI $1.04-1.23)$. On the other hand, the TCC combination showed a protective effect for SSc (Bonferroni p $=0.020$, OR 0.82, 95\% CI $0.72-0.94)$, but statistical significance was lost when sex was included as a covariate ( $\mathrm{p}=0.117$; Table 2$)$. In addition, metaanalysis for the different IL6 allelic combinations in the different subtypes of patients with SSc showed that the associated $I L 6^{*} \mathrm{GGC}$ allelic combination with global disease seemed to confer a similar effect (size and direction) in both

Table 1. Genotype and minor allele frequencies of SNP located within IL6 gene in patients with SSc and healthy controls of the different study cohorts.

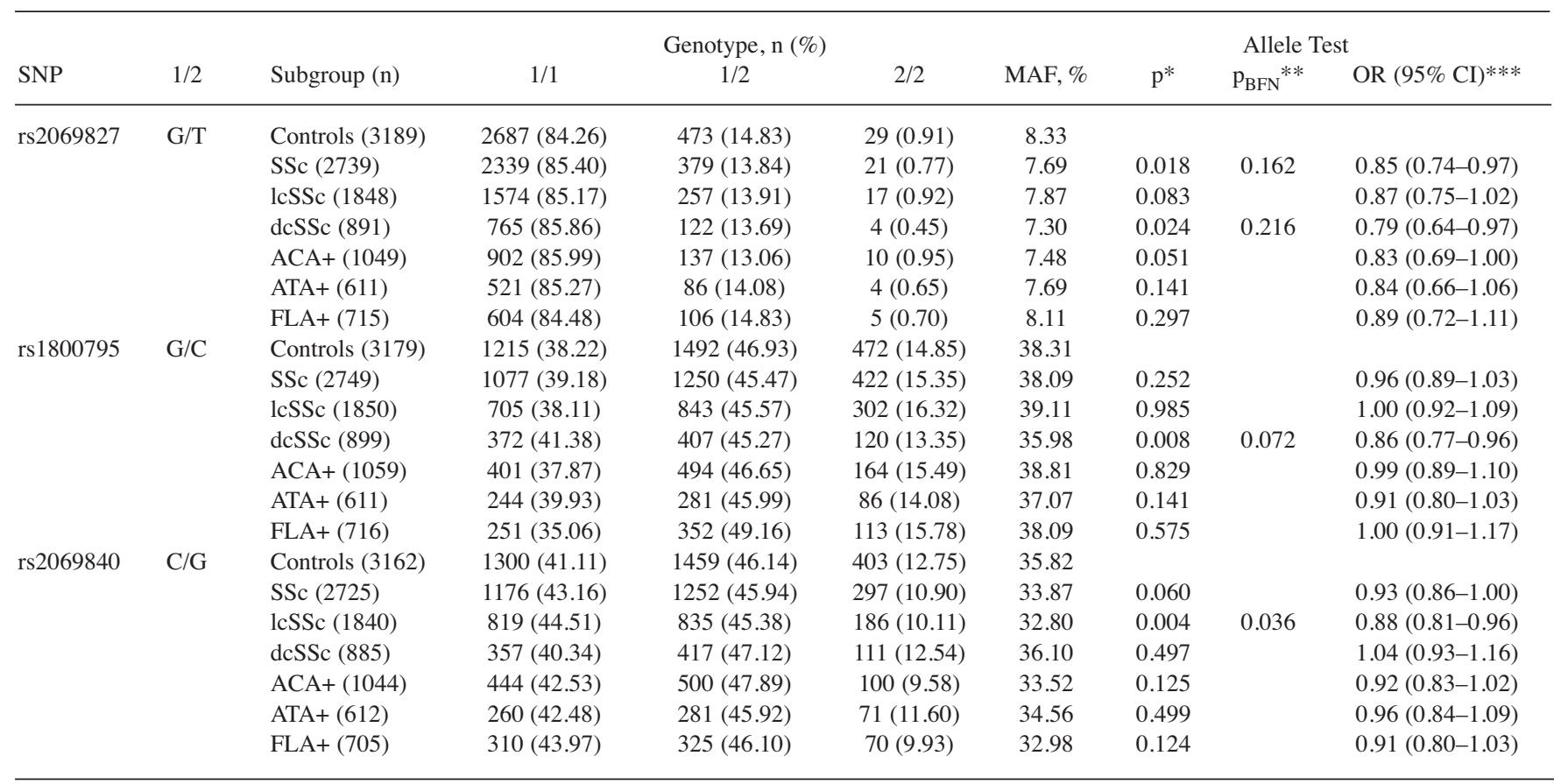

* Values calculated for the allelic model and Mantel-Haenszel test under fixed effect. ** Multiple testing Bonferroni (BFN) correction. *** For the minor allele. SSc: systemic sclerosis; lcSSc: limited cutaneous SSc; dcSSc: diffuse cutaneous SSc; ACA: anticentromere antibodies; ATA: antitopoisomerase antibodies; FLA: fibrotic lung; MAF: minor allele frequency; SNP: single-nucleotide polymorphism. 
Table 2. Pooled analysis of rs2069827-rs1800795-rs2069840 allelic combinations in white patients with SSc and healthy controls.

\begin{tabular}{lccccc}
\hline Allelic Combination & SSc, $(\%)$ & Controls, $\mathrm{n}(\%)$ & $\mathrm{p}_{\mathrm{MH}}$ & $\begin{array}{c}\mathrm{p} \text { (covariates } \\
\text { sex and population) }\end{array}$ & OR (95\% CI) \\
\hline GGC & $1598(28.4)$ & $1710(26.5)$ & $0.016^{*}$ & 0.014 & $1.13(1.04-1.23)$ \\
GCC & $1693(30.1)$ & $1915(29.7)$ & 0.980 & 0.455 & $1.00(0.93-1.09)$ \\
GGG & $1920(34.1)$ & $2289(35.5)$ & 0.280 & 0.014 & $0.95(0.88-1.03)$ \\
TCC & $419(7.4)$ & $534(8.3)$ & $0.020^{*}$ & 0.117 & $0.82(0.72-0.94)$ \\
\hline
\end{tabular}

$\mathrm{p}_{\mathrm{MH}}$ : allelic Mantel-Haenszel fixed-effects model. $\mathrm{p}_{\mathrm{BD}}$ : Breslow-Day value. * Multiple testing Bonferroni correction ( $\times 4$ analyzed haplotypes).

subgroups of patients (lcSSc and dcSSc) although, probably because of statistical power, in the comparison of dcSSc against controls, statistical significance was lost (Appendix 8, Appendix 9).

An association was evident when the minor allele frequencies of the rs2069840 genetic variant were tested in patients with lcSSc versus controls (Bonferroni $\mathrm{p}=0.036$, OR $0.88,95 \%$ CI $0.81-0.96$ ), whereas the rs 2069840 minor allele frequencies were similar between the dcSSc subgroup and controls $\left(\mathrm{p}_{\text {uncorrected }}=0.497\right.$, OR $1.04,95 \%$ CI $0.93-1.16)$. For this reason, in the allelic combination analysis the $I L 6^{*} \mathrm{GGG}$ combination showed a risk effect for global disease, although haplotype analysis in the different subtypes of patients revealed that this allelic combination, which is marked for the rs $2069840 * \mathrm{G}$ allele, confers risk for only the limited clinical disease form (Appendix 8, Appendix 9).

A trend for association was also evident when the minor allele frequencies of the rs 1800795 variant were compared between cases with dcSSc and controls (Bonferroni $\mathrm{p}=$ 0.072 , OR $0.86,95 \%$ CI $0.77-0.96$ ), while the rs 1800795 minor allele frequencies were similar between lcSSc and controls ( $\mathrm{p}_{\text {uncorrected }}=0.985$, OR $1.00,95 \%$ CI $0.92-1.09$ ).

Finally, the analysis according to autoantibody status (ACA/ATA) or development of pulmonary fibrosis achieved no statistical significance in either the independent analyses (Table 1) or the allelic combination tests (data not shown).

\section{DISCUSSION}

The cytokine IL-6 plays an important role in immunity and fibrosis, both key aspects of $\mathrm{SSc}^{9}$. To date, several GWAS have led to the discovery of many common genetic variants associated with SSc. However, SNP located within IL6 locus have not been associated with SSc in these studies ${ }^{4,5,6}$. Even though genome-wide studies of SSc susceptibility did not highlight the association with this locus, poor coverage of the specific chromosomal region in these studies might hamper identification of genetic risk factors. It is important to note that the SNP analyzed in our study were not included in previous GWAS data and, as well, the IL6 region has not been properly covered in GWAS ${ }^{4}$. In addition, it should be noted that the allelic combination analyses often help to uncover hidden signals. Thus, the allelic combinations may also tag other regional polymorphic sites, and therefore they are considered to provide more robust results than the study of single SNP in unraveling the genetic background of complex diseases. Indeed, our data showed that the IL $6^{*} \mathrm{GGC}$ allelic combination influences predisposition to SSc, conferring risk to the global disease. This associated allelic combination may contain the causal genetic variant or may act as a marker of another nearby causal polymorphism in tight linkage disequilibrium with it. However, further comprehensive studies are needed to elucidate causal polymor$\mathrm{phism} / \mathrm{s}$ of the detected associations.

To date few and relatively underpowered studies have been conducted to analyze the influence of the IL 6 gene in susceptibility to SSc, and results have been controver$\mathrm{sial}^{24,25}$. Moreover, these studies assessed only the rs 1800795 polymorphism $(-174 \mathrm{G} / \mathrm{C})$ and this may provide a limited view of the role of IL6 in SSc pathophysiology, because several polymorphisms are likely to modify levels of IL- $6^{24,25,26}$. Our investigation is the first tagging study to explore the influence of most of the IL6 gene variability in the susceptibility to SSc and/or its major clinical features in a large and well-defined white cohort.

Interestingly, the $I L 6$ rs 1800795 (-174G) variant, reported to increase the levels of IL- $6^{19}$, is carried in 2 of the 4 commonly conformed IL 6 allelic combinations $\left(\mathrm{GG}^{*} \mathrm{C}\right.$ and $\mathrm{GG}^{*} \mathrm{G}$ ). We investigated the effects of these 2 combinations in the development of SSc. Our results showed that only the $\mathrm{GG}^{*} \mathrm{C}$ combination confers risk for the global disease, suggesting that IL6 rs1800795 may not confer disease susceptibility by itself, and other variant/s carried in the $\mathrm{GG}^{*} \mathrm{C}$ combination could be necessary to confer the described effect (Table 2). Thus, our results are in agreement with studies showing that several polymorphisms influence final IL-6 levels ${ }^{18}$.

Additionally, we observed that the IL6 rs $2069840 * \mathrm{G}$ seems to play a protective role in the lcSSc clinical form, whereas the rs $1800795^{*} \mathrm{G}$ allele seems to confer risk for the $\mathrm{dcSSc}$ clinical form. A recent study showed overexpression of IL-6 in patients with dcSSc and supports the potential of IL-6 as a surrogate marker for clinical outcome in $\mathrm{SSc}^{27}$. Other studies have suggested that blocking Th17-inducing cytokines such as IL-6 and IL-23 may intervene in the progression of $\mathrm{SSc}^{13}$. Our results would be in agreement with

Personal non-commercial use only. The Journal of Rheumatology Copyright @ 2012 . All rights reserved. 
these functional studies, and genetic variants located within the IL6 locus affecting the final IL-6 levels probably influence specific subgroups of patients with SSc.

Because the pathogenesis of SSc is still unclear, an improved treatment for SSc is a major challenge. Our results might open new fields of study for treatment of SSc, and further investigations are needed to determine the role of the IL6 locus in this genetically complex autoimmune disorder.

\section{ACKNOWLEDGMENT}

The authors thank Sofía Vargas, Sonia García, and Gema Robledo (Instituto de Parasitología y Biomedicina López-Neyra, CSIC, Spain) for excellent technical assistance, and all the patients and controls for kindly providing their essential collaboration. We thank Banco Nacional de ADN (University of Salamanca, Spain) for supplying part of the control material.

\section{APPENDIX 1}

List of study collaborators. The Spanish Scleroderma Group: Norberto Ortego-Centeno and Raquel Ríos, Unidad de Enfermedades Sistémicas Autoinmunes, Servicio de Medicina Interna, Hospital Clínico Universitario San Cecilio, Granada; Nuria Navarrete, Servicio de Medicina Interna, Hospital Virgen de las Nieves, Granada; María Teresa Camps, Servicio de Medicina Interna, Hospital Carlos Haya, Málaga; Antonio Fernández-Nebro, Servicio de Reumatología, Hospital Carlos Haya, Málaga; María F. González-Escribano, Servicio de Inmunología, Hospital Virgen del Rocío, Sevilla; Julio Sánchez-Román and M. Jesús Castillo, Servicio de Medicina Interna, Hospital Virgen del Rocío, Sevilla; M. lÁngeles Aguirre, Servicio de Reumatología, Hospital Reina Sofía, Córdoba; Benjamín Fernández-Gutiérrez and Luis Rodríguez-Rodríguez, Servicio de Reumatología, Hospital Clínico San Carlos, Madrid; Esther Vicente, Servicio de Reumatología, Hospital La Princesa, Madrid; José Luis Andreu and Mónica Fernández de Castro, Servicio de Reumatología, Hospital Puerta del Hierro, Madrid; Lina Martínez, Servicio de Reumatología, Hospital General Universitario Gregorio Marañón, Madrid;
Iván Castellví, Servicio de Reumatología, Hospital Sant Pau, Barcelona; Anna Pros, Servicio de Reumatología, Hospital Del Mar, Barcelona; Mónica Rodríguez Carballeira, Servicio de Medicina Interna, Hospital Universitari Mútua Terrassa, Barcelona; Raquel López Mejías, Servicio de Reumatología, Hospital Universitario Marqués de Valdecilla, Santander; Bernardino Díaz and Luis Trapiella, Servicio de Medicina Interna, Hospital Central de Asturias, Oviedo; María del Carmen Freire and Inés Vaqueiro, Unidad de Trombosis y Vasculitis, Servicio de Medicina Interna, Hospital Xeral-Complexo Hospitalario Universitario de Vigo, Vigo; Luis SáezComet, Unidad de Enfermedades Autoinmunes Sistémicas, Servicio de Medicina Interna, Hospital Universitario Miguel Servet, Zaragoza; Federico Díaz and Vanesa Hernández, Servicio de Reumatología, Hospital Universitario de Canarias, Tenerife; Emma Beltrán, Servicio de Reumatología, Hospital del Doctor Peset Aleixandre, Valencia; María Ángeles Robles and Natividad Oreiro, Servicio de Reumatología, INIBIC-Hospital Universitario A Coruña, La Coruña, Spain.

\section{REFERENCES}

1. Gabrielli A, Avvedimento EV, Krieg T. Scleroderma. N Engl J Med 2009;360:1989-2003

2. Mayes MD. Scleroderma epidemiology. Rheum Dis Clin North Am 2003;29:239-54.

3. Martin JE, Bossini-Castillo L, Martin J. Unraveling the genetic component of systemic sclerosis. Hum Genet 2012;131:1023-37.

4. Radstake TR, Gorlova O, Rueda B, Martin JE, Alizadeh BZ, Palomino-Morales R, et al. Genome-wide association study of systemic sclerosis identifies CD247 as a new susceptibility locus. Nat Genet 2010;42:426-9.

5. Allanore Y, Saad M, Dieude P, Avouac J, Distler JH, Amouyel P, et al. Genome-wide scan identifies TNIP1, PSORS1C1, and RHOB as novel risk loci for systemic sclerosis. PLoS Genet 2011; 7:e1002091.

6. Gorlova O, Martin JE, Rueda B, Koeleman BP, Ying J, Teruel M, et al. Identification of novel genetic markers associated with clinical phenotypes of systemic sclerosis through a genome-wide association strategy. PLoS Genet 2011;7:e1002178.

\section{APPENDIX 2}

Genotype and minor allele frequencies of SNP within IL6 gene in patients with SSc and healthy controls from Germany.

\begin{tabular}{|c|c|c|c|c|c|c|c|c|c|c|c|}
\hline \multirow[b]{2}{*}{ CHR } & \multirow[b]{2}{*}{ SNP } & \multirow[b]{2}{*}{ Locus } & \multirow[b]{2}{*}{$1 / 2$} & \multirow[b]{2}{*}{ Subgroup (n) } & \multicolumn{3}{|c|}{ Genotype, n (\%) } & \multirow[b]{2}{*}{ MAF, $\%$} & \multicolumn{2}{|c|}{ Allele Test } & \multirow[b]{2}{*}{ OR $(95 \% \mathrm{CI}) * * *$} \\
\hline & & & & & $1 / 1$ & $1 / 2$ & $2 / 2$ & & $\mathrm{p}^{*}$ & $\mathrm{p}_{\mathrm{FDR}} * *$ & \\
\hline \multirow[t]{4}{*}{7} & rs2069827 & IL6 & $\mathrm{G} / \mathrm{T}$ & Controls (289) & $226(78.20)$ & $57(19.72)$ & $6(2.08)$ & 11.94 & & & \\
\hline & & & & lcSSc (338) & 267 (78.99) & $67(19.82)$ & $4(1.18)$ & 11.09 & 0.64 & 0.90 & $0.92(0.65-1.30)$ \\
\hline & & & & $\mathrm{dcSSc}(241)$ & $199(82.57)$ & $40(16.60)$ & $2(0.83)$ & 9.13 & 0.14 & 0.21 & $0.74(0.50-1.11)$ \\
\hline & & & & $\mathrm{ACA}+(224)$ & $182(81.25)$ & $39(17.41)$ & $3(1.34)$ & 10.04 & 0.34 & 0.51 & $0.82(0.55-1.23)$ \\
\hline \multirow{5}{*}{7} & & & & SSc $(568)$ & 205 (36.09) & $262(46.13)$ & $101(17.78)$ & 40.85 & 0.05 & 0.14 & $0.82(0.67-1.00)$ \\
\hline & & & & lcSSc (331) & $112(33.84)$ & $158(47.73)$ & $61(18.43)$ & 42.30 & 0.21 & 0.62 & $0.87(0.69-1.08)$ \\
\hline & & & & $\operatorname{dcSSc}(237)$ & $93(39.24)$ & $104(43.88)$ & $40(16.88)$ & 38.82 & 0.02 & 0.06 & $0.75(0.59-0.96)$ \\
\hline & & & & $\mathrm{ACA}+(219)$ & 79 (36.07) & $105(47.95)$ & 35 (15.98) & 39.95 & 0.06 & 0.18 & $0.79(0.61-1.01)$ \\
\hline & & & & ATA+ (189) & 75 (39.68) & $81(42.86)$ & $33(17.46)$ & 38.89 & 0.03 & 0.10 & $0.75(0.58-0.98)$ \\
\hline \multirow[t]{2}{*}{7} & rs2069840 & IL6 & $\mathrm{C} / \mathrm{G}$ & Controls (287) & $125(43.55)$ & $136(47.39)$ & $26(9.06)$ & 32.75 & & & \\
\hline & & & & ATA+ (189) & $84(44.44)$ & $78(41.27)$ & 27 (14.29) & 34.92 & 0.49 & 0.49 & $1.10(0.84-1.45)$ \\
\hline
\end{tabular}

\footnotetext{
* Values calculated for the allelic model. ** Multiple testing false discovery rate correction. *** For the minor allele. SNP: single-nucleotide polymorphism;
} IL: interleukin; SSc: systemic sclerosis; MAF: minor allele frequency. 
APPENDIX 3

Genotype and minor allele frequencies of SNP within IL6 gene in patients with SSc and healthy controls from Sweden.

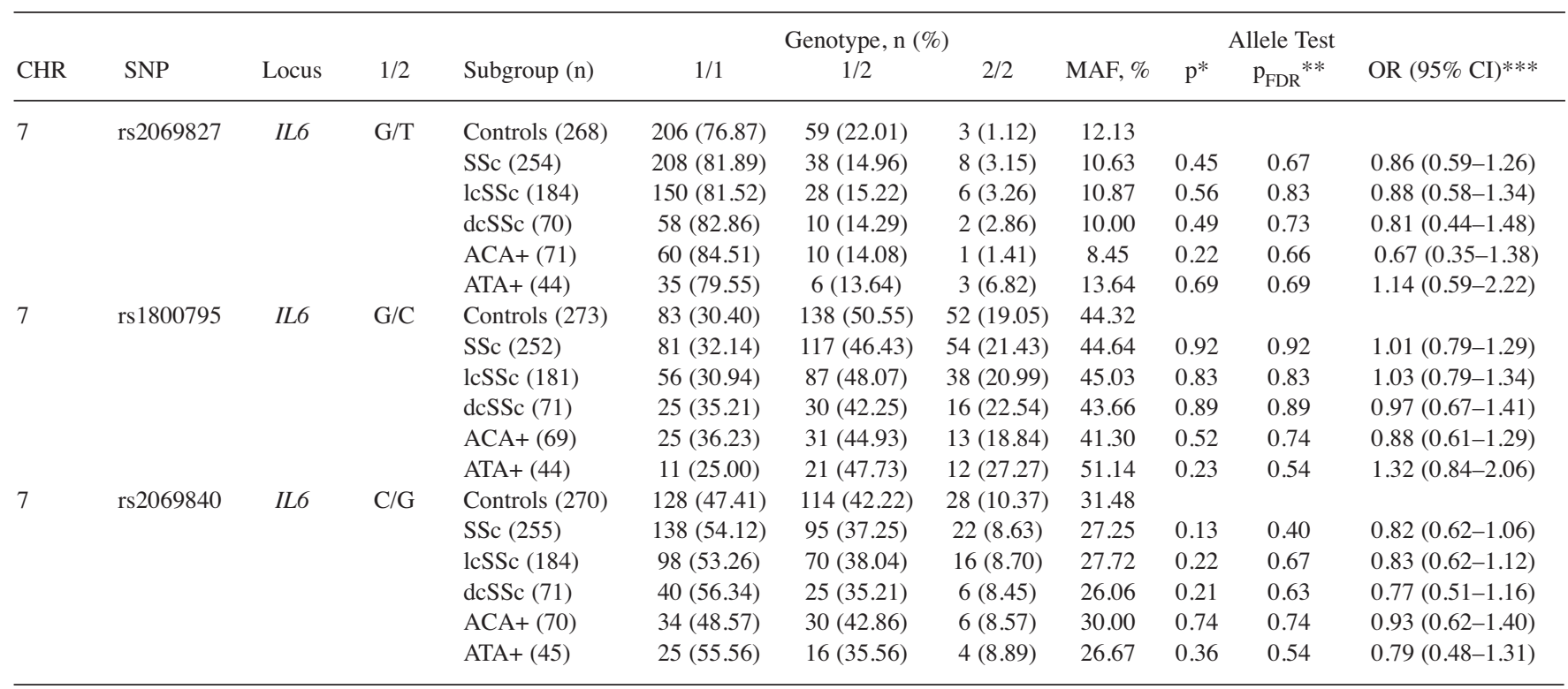

* Values calculated for the allelic model. ** Multiple testing false discovery rate correction. *** For the minor allele. SNP: single-nucleotide polymorphism; IL: interleukin; SSc: systemic sclerosis; MAF: minor allele frequency.

\section{APPENDIX 4}

Genotype and minor allele frequencies of SNP within IL6 gene in patients with SSc and healthy controls from The Netherlands.

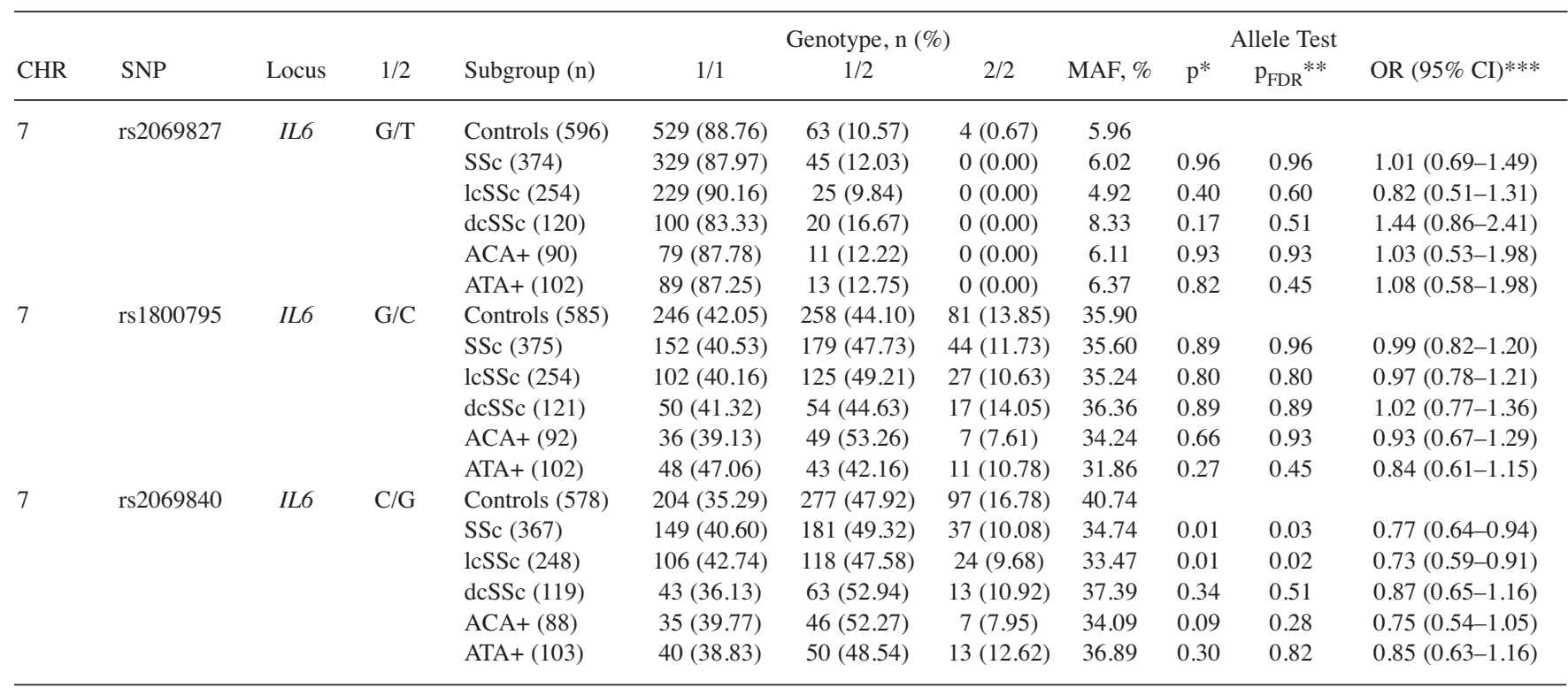

* Values calculated for the allelic model. ** Multiple testing false discovery rate correction. *** For the minor allele. SNP: single-nucleotide polymorphism; IL: interleukin; SSc: systemic sclerosis; MAF: minor allele frequency.

7. Kishimoto T. Interleukin-6: From basic science to medicine -40 years in immunology. Annu Rev Immunol 2005;23:1-21.

8. Feghali CA, Bost KL, Boulware DW, Levy LS. Mechanisms of pathogenesis in scleroderma. I. Overproduction of interleukin 6 by fibroblasts cultured from affected skin sites of patients with scleroderma. J Rheumatol 1992;19:1207-11.
9. Barnes TC, Anderson ME, Moots RJ. The many faces of interleukin-6: The role of IL-6 in inflammation, vasculopathy, and fibrosis in systemic sclerosis. Int J Rheumatol 2011;2011:721608.

10. Sato S, Hasegawa M, Takehara K. Serum levels of interleukin-6 and interleukin-10 correlate with total skin thickness score in patients with systemic sclerosis. J Dermatol Sci 2001;27:140-6. 


\section{APPENDIX 5}

Genotype and minor allele frequencies of SNP within IL6 gene in patients with SSc and healthy controls from Spain.

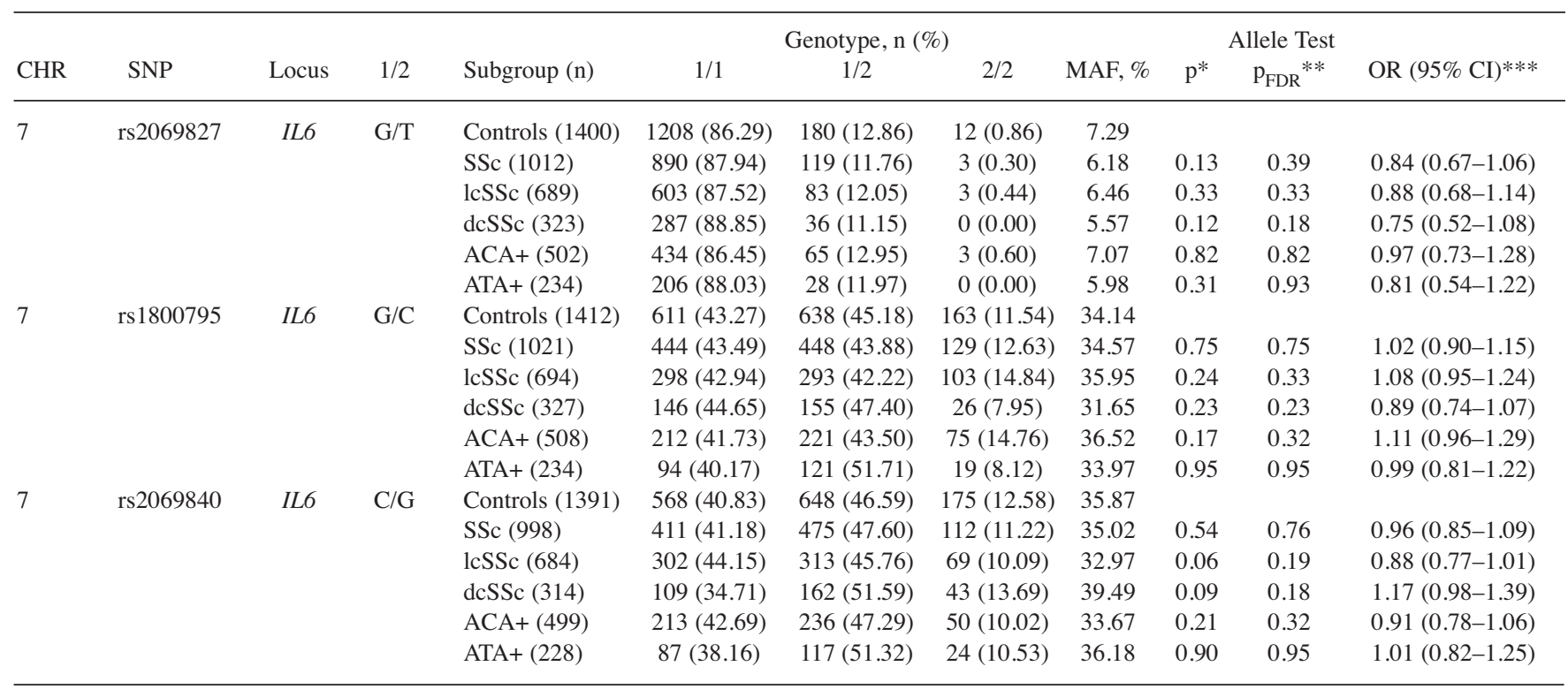

* Values calculated for the allelic model. ** Multiple testing false discovery rate correction. *** For the minor allele. SNP: single-nucleotide polymorphism; IL: interleukin; SSc: systemic sclerosis; MAF: minor allele frequency.

\section{APPENDIX 6}

Genotype and minor allele frequencies of SNP within IL6 gene in patients with SSc and healthy controls from the United Kingdom.

\begin{tabular}{|c|c|c|c|c|c|c|c|c|c|c|c|}
\hline \multirow[b]{2}{*}{ CHR } & \multirow[b]{2}{*}{ SNP } & \multirow[b]{2}{*}{ Locus } & \multirow[b]{2}{*}{$1 / 2$} & \multirow[b]{2}{*}{ Subgroup (n) } & \multicolumn{3}{|c|}{ Genotype, n (\%) } & \multicolumn{4}{|c|}{ Allele Test } \\
\hline & & & & & $1 / 1$ & $1 / 2$ & $2 / 2$ & MAF, $\%$ & $\mathrm{p}^{*}$ & $\mathrm{p}_{\mathrm{FDR}} * *$ & OR $(95 \% \mathrm{CI})^{* * *}$ \\
\hline \multirow[t]{4}{*}{7} & \multirow[t]{4}{*}{ rs 2069827} & \multirow[t]{4}{*}{ IL6 } & \multirow[t]{4}{*}{$\mathrm{G} / \mathrm{T}$} & Controls (376) & 305 (81.12) & 68 (18.09) & $3(0.80)$ & 9.84 & & & \\
\hline & & & & $\operatorname{lcSSc}(316)$ & $273(86.39)$ & $40(12.66)$ & $3(0.95)$ & 7.28 & 0.09 & 0.27 & $0.72(0.49-1.06)$ \\
\hline & & & & $\operatorname{dcSSc}(104)$ & $90(86.54)$ & $14(13.46)$ & $0(0.00)$ & 6.73 & 0.17 & 0.25 & $0.66(0.37-1.20)$ \\
\hline & & & & $\mathrm{ACA}+(160)$ & $144(90.00)$ & $14(8.75)$ & $2(1.25)$ & 5.63 & 0.02 & 0.07 & $0.55(0.32-0.93)$ \\
\hline \multirow{5}{*}{7} & \multirow{5}{*}{ rs 1800795} & \multirow{5}{*}{ IL6 } & \multirow{5}{*}{$\mathrm{G} / \mathrm{C}$} & SSc (434) & $168(38.71)$ & $189(43.55)$ & 77 (17.74) & 39.52 & 0.14 & 0.21 & $0.86(0.71-1.05)$ \\
\hline & & & & lcSSc (323) & $122(37.77)$ & $143(44.27)$ & $58(17.96)$ & 40.09 & 0.25 & 0.37 & $0.88(0.71-1.09)$ \\
\hline & & & & $\mathrm{dcSSc}(111)$ & $46(41.44)$ & $46(41.44)$ & $19(17.12)$ & 37.84 & 0.16 & 0.25 & $0.80(0.59-1.09)$ \\
\hline & & & & $\mathrm{ACA}+(169)$ & $55(32.54)$ & $86(50.89)$ & $28(16.57)$ & 42.01 & 0.72 & 0.91 & $0.95(0.74-1.24)$ \\
\hline & & & & ATA+ (59) & $23(38.98)$ & $25(42.37)$ & $11(18.64)$ & 39.83 & 0.50 & 0.50 & $0.87(0.59-1.30)$ \\
\hline \multirow[t]{2}{*}{7} & \multirow[t]{2}{*}{ rs2069840 } & \multirow[t]{2}{*}{ IL6 } & \multirow[t]{2}{*}{$\mathrm{C} / \mathrm{G}$} & Controls (376) & $157(41.76)$ & $171(45.48)$ & $48(12.77)$ & 35.51 & & & \\
\hline & & & & $\mathrm{ATA}+(62)$ & $33(53.23)$ & $23(37.10)$ & $6(9.68)$ & 28.23 & 0.11 & 0.28 & $0.71(0.47-1.09)$ \\
\hline
\end{tabular}

* Values calculated for the allelic model. ** Multiple testing false discovery rate correction. *** For the minor allele. SNP: single-nucleotide polymorphism;

IL: interleukin; SSc: systemic sclerosis; MAF: minor allele frequency.

11. Hasegawa M, Sato S, Fujimoto M, Ihn H, Kikuchi K, Takehara K. Serum levels of interleukin 6 (IL-6), oncostatin M, soluble IL-6 receptor, and soluble gp130 in patients with systemic sclerosis. J Rheumatol 1998;25:308-13.

12. Hasegawa M, Sato S, Ihn H, Takehara K. Enhanced production of interleukin-6 (IL-6), oncostatin M and soluble IL-6 receptor by cultured peripheral blood mononuclear cells from patients with systemic sclerosis. Rheumatology 1999;38:612-7.

13. Radstake TR, van Bon L, Broen J, Hussiani A, Hesselstrand R, Wuttge DM, et al. The pronounced Th17 profile in systemic sclerosis (SSc) together with intracellular expression of TGF-beta and IFN-gamma distinguishes SSc phenotypes. PLoS One 2009;4:e5903.

14. Stockinger B, Veldhoen M. Differentiation and function of Th17 T 


\section{APPENDIX 7}

Genotype and minor allele frequencies of SNP within IL6 gene in patients with SSc and healthy controls from Norway.

\begin{tabular}{|c|c|c|c|c|c|c|c|c|c|c|c|}
\hline \multirow[b]{2}{*}{ CHR } & \multirow[b]{2}{*}{ SNP } & \multirow[b]{2}{*}{ Locus } & \multirow[b]{2}{*}{$1 / 2$} & \multirow[b]{2}{*}{ Subgroup (n) } & \multicolumn{3}{|c|}{ Genotype, n (\%) } & \multirow[b]{2}{*}{ MAF, $\%$} & \multicolumn{2}{|c|}{ Allele Test } & \multirow[b]{2}{*}{ OR $(95 \% \mathrm{CI})^{* * *}$} \\
\hline & & & & & $1 / 1$ & $1 / 2$ & $2 / 2$ & & $\mathrm{p}^{*}$ & $\mathrm{p}_{\mathrm{FDR}} * *$ & \\
\hline \multirow[t]{4}{*}{7} & rs2069827 & IL6 & $\mathrm{G} / \mathrm{T}$ & Controls (260) & $213(81.92)$ & $46(17.69)$ & $1(0.38)$ & 9.23 & & & \\
\hline & & & & lcSSc (67) & $52(77.61)$ & $14(20.90)$ & $1(1.49)$ & 11.94 & 0.35 & 0.35 & $1.33(0.73-2.43)$ \\
\hline & & & & dcSSc (33) & $31(93.94)$ & $2(6.06)$ & $0(0.00)$ & 3.03 & 0.09 & 0.15 & $0.31(0.07-1.30)$ \\
\hline & & & & $\mathrm{ACA}+(54)$ & $44(81.48)$ & $9(16.67)$ & $1(1.85)$ & 10.19 & 0.76 & 0.82 & $1.12(0.56-2.23)$ \\
\hline \multirow{5}{*}{7} & & & & SSc (99) & $27(27.27)$ & $55(55.56)$ & $17(17.17)$ & 44.95 & 0.97 & 0.97 & $0.99(0.71-1.38)$ \\
\hline & & & & lcSSc (67) & 15 (22.39) & $37(55.22)$ & 15 (22.39) & 50.00 & 0.32 & 0.35 & $1.22(0.83-1.78)$ \\
\hline & & & & dcSSc (32) & $12(37.50)$ & $18(56.25)$ & $2(6.25)$ & 34.38 & 0.10 & 0.15 & $0.64(0.37-1.10)$ \\
\hline & & & & $\mathrm{ACA}+(54)$ & $16(29.63)$ & $26(48.15)$ & $12(22.22)$ & 46.30 & 0.82 & 0.82 & $1.05(0.69-1.59)$ \\
\hline & & & & $\mathrm{ATA}+(14)$ & $7(50.00)$ & $5(35.71)$ & $2(14.29)$ & 32.14 & 0.18 & 0.31 & $0.58(0.26-1.30)$ \\
\hline \multirow[t]{2}{*}{7} & rs2069840 & IL6 & $\mathrm{C} / \mathrm{G}$ & Controls (260) & $118(45.38)$ & $113(43.46)$ & $29(11.15)$ & 32.88 & & & \\
\hline & & & & $\mathrm{ATA}+(14)$ & $4(28.57)$ & $8(57.14)$ & $2(14.29)$ & 42.86 & 0.28 & 0.31 & $1.53(0.71-3.31)$ \\
\hline
\end{tabular}

* Values calculated for the allelic model. ** Multiple testing false discovery rate correction. *** For the minor allele. SNP: single-nucleotide polymorphism; IL: interleukin; SSc: systemic sclerosis; MAF: minor allele frequency.

\section{APPENDIX 8}

Pooled analysis of rs2069827-rs1800795-rs2069840 allelic combinations in white patients with dcSSc and healthy controls.

\begin{tabular}{|c|c|c|c|c|c|c|}
\hline Haplotype & $\begin{array}{c}\mathrm{dcSSc}, \mathrm{n}(\%) \\
\mathrm{n}=1822\end{array}$ & $\begin{array}{l}\text { Controls, n (\%), } \\
\mathrm{n}=6448\end{array}$ & $\mathrm{p}_{\mathrm{MH}}$ & $\begin{array}{c}\mathrm{p} \\
\text { (covariates sex } \\
\text { and population) }\end{array}$ & OR $(95 \% \mathrm{CI})$ & $\mathrm{p}_{\mathrm{BD}}$ \\
\hline GCC & $518(28.4)$ & $1915(29.7)$ & 0.171 & 0.494 & $0.92(0.82-1.04)$ & 0.9 \\
\hline GGG & $648(35.6)$ & $2289(35.5)$ & 0.642 & 0.806 & $1.03(0.92-1.15)$ & 0.14 \\
\hline TCC & $131(7.2)$ & $534(8.3)$ & $0.080^{*}$ & 0.089 & $0.78(0.64-0.96)$ & 0.24 \\
\hline
\end{tabular}

$\mathrm{p}_{\mathrm{MH}}$ : allelic Mantel-Haenszel fixed-effects model. $\mathrm{p}_{\mathrm{BD}}$ : Breslow-Day value. * Multiple testing Bonferroni correction $(\times 4$ analyzed haplotypes). dcSSc: diffuse cutaneous systemic sclerosis.

\section{APPENDIX 9}

Pooled analysis of rs2069827-rs1800795-rs2069840 allelic combinations in white patients with lcSSc and healthy controls.

\begin{tabular}{|c|c|c|c|c|c|c|}
\hline Haplotype & $\begin{array}{c}\mathrm{lcSSc}, \mathrm{n}(\%), \\
\mathrm{n}=3765\end{array}$ & $\begin{array}{c}\text { Controls, } \mathrm{n}(\%) \\
\mathrm{n}=6448\end{array}$ & $\mathrm{p}_{\mathrm{MH}}$ & $\begin{array}{c}\mathrm{p} \\
\text { (covariates sex } \\
\text { and population) }\end{array}$ & OR $(95 \% \mathrm{CI})$ & $\mathrm{p}_{\mathrm{BD}}$ \\
\hline GCC & $1176(30.2)$ & 1915 (29.7) & 0.180 & 0.149 & $1.06(0.97-1.17)$ & 0.69 \\
\hline GGG & 1228 (32.6) & 2289 (35.5) & $0.024 *$ & 0.001 & $0.89(0.81-0.97)$ & 0.40 \\
\hline TCC & $288(7.6)$ & $534(8.3)$ & $0.160 *$ & 0.185 & $0.85(0.73-0.99)$ & 0.60 \\
\hline
\end{tabular}

$\mathrm{p}_{\mathrm{MH}}$ : allelic Mantel-Haenszel fixed-effects model. $\mathrm{p}_{\mathrm{BD}}$ : Breslow-Day value. * Multiple testing Bonferroni correction ( $\times 4$ analyzed haplotypes). lcSSc: limited cutaneous systemic sclerosis. 
cells. Curr Opin Immunol 2007;19:281-6.

15. Deleuran B, Abraham DJ. Possible implication of the effector CD4+ T-cell subpopulation TH17 in the pathogenesis of systemic scleroderma. Nat Clin Pract Rheumatol 2007;3:682-3.

16. Shima Y, Kuwahara Y, Murota H, Kitaba S, Kawai M, Hirano T, et al. The skin of patients with systemic sclerosis softened during the treatment with anti-IL-6 receptor antibody tocilizumab. Rheumatology 2010;49:2408-12.

17. Terry CF, Loukaci V, Green FR. Cooperative influence of genetic polymorphisms on interleukin 6 transcriptional regulation. J Biol Chem 2000;275:18138-44.

18. Fife MS, Ogilvie EM, Kelberman D, Samuel J, Gutierrez A, Humphries SE, et al. Novel IL-6 haplotypes and disease association. Genes Immun 2005;6:367-70.

19. Fishman D, Faulds G, Jeffery R, Mohamed-Ali V, Yudkin JS, Humphries S, et al. The effect of novel polymorphisms in the interleukin-6 (IL-6) gene on IL-6 transcription and plasma IL-6 levels, and an association with systemic-onset juvenile chronic arthritis. J Clin Invest 1998;102:1369-76.

20. Schotte H, Schluter B, Rust S, Assmann G, Domschke W, Gaubitz M. Interleukin-6 promoter polymorphism $(-174 \mathrm{G} / \mathrm{C})$ in Caucasian German patients with systemic lupus erythematosus. Rheumatology 2001;40:393-400.

21. Preliminary criteria for the classification of systemic sclerosis (scleroderma). Subcommittee for scleroderma criteria of the American Rheumatism Association Diagnostic and Therapeutic Criteria Committee. Arthritis Rheum 1980;23:581-90.
22. LeRoy EC, Black C, Fleischmajer R, Jablonska S, Krieg T, Medsger TA Jr, et al. Scleroderma (systemic sclerosis): Classification, subsets and pathogenesis. J Rheumatol 1988; 15:202-5.

23. Dieude P, Dawidowicz K, Guedj M, Legrain Y, Wipff J, Hachulla E, et al. Phenotype-haplotype correlation of IRF5 in systemic sclerosis: Role of 2 haplotypes in disease severity. J Rheumatol 2010;37:987-92.

24. Sfrent-Cornateanu R, Mihai C, Balan S, Ionescu R, Moldoveanu E. The IL-6 promoter polymorphism is associated with disease activity and disability in systemic sclerosis. J Cell Mol Med 2006;10:955-9.

25. Beretta L, Santaniello A, Cappiello F, Barili M, Scorza R. No evidence for a role of the proximal IL- 6 G/C -174 single nucleotide polymorphism in Italian patients with systemic sclerosis. J Cell Mol Med 2007;11:896-8; author reply 8-9.

26. Endler G, Marsik C, Joukhadar C, Marculescu R, Mayr F, Mannhalter C, et al. The interleukin-6 G(-174)C promoter polymorphism does not determine plasma interleukin-6 concentrations in experimental endotoxemia in humans. Clin Chem 2004;50:195-200

27. Khan K, Xu S, Nihtyanova S, Derrett-Smith E, Abraham D, Denton $\mathrm{CP}$, et al. Clinical and pathological significance of interleukin 6 overexpression in systemic sclerosis. Ann Rheum Dis 2012;71:1235-42. 